\title{
QUEEN'S
UNIVERSITY
BELFAST
}

\section{Impact of Free Glasses and a Teacher Incentive on Children's Use of Eyeglasses: A Cluster-Randomized Controlled Trial.}

\author{
Yi, H., Zhang, H., Ma, X., Zhang, L., Wang, X., Jin, L., Naidoo, K., Minto, H., Zou, H., Lu, L., Rozelle, S., \& \\ Congdon, N. (2015). Impact of Free Glasses and a Teacher Incentive on Children's Use of Eyeglasses: A \\ Cluster-Randomized Controlled Trial. American Journal of Ophthalmology, 160(5), 889-896. \\ https://doi.org/10.1016/j.ajo.2015.08.006
}

Published in:

American Journal of Ophthalmology

Document Version:

Early version, also known as pre-print

Queen's University Belfast - Research Portal:

Link to publication record in Queen's University Belfast Research Portal

Publisher rights

(C) 2015 The Authors

\section{General rights}

Copyright for the publications made accessible via the Queen's University Belfast Research Portal is retained by the author(s) and / or other copyright owners and it is a condition of accessing these publications that users recognise and abide by the legal requirements associated with these rights.

Take down policy

The Research Portal is Queen's institutional repository that provides access to Queen's research output. Every effort has been made to ensure that content in the Research Portal does not infringe any person's rights, or applicable UK laws. If you discover content in the Research Portal that you believe breaches copyright or violates any law, please contact openaccess@qub.ac.uk. 


\section{Elsevier Editorial System(tm) for American Journal of Ophthalmology Manuscript Draft}

Manuscript Number: AJ0-15-534R2

Title: Impact of Free Glasses and a Teacher Incentive on Children's Use of Eyeglasses: A ClusterRandomized Controlled Trial

Article Type: Original Article

Keywords: Myopia; children; eyeglasses; China; migrant; compliance; teacher incentive

Corresponding Author: Dr. Nathan Congdon, MD, MPH

Corresponding Author's Institution: Zhongshan Ophthalmic Center

First Author: Hongmei Yi

Order of Authors: Hongmei Yi; Haiqing Zhang; Xiaochen Ma; Linxiu Zhang; Xiuqin Wang; Ling Jin; Kovin Naidoo; Hasan Minto; Haidong Zou; Lina Lu; Scott Rozelle; Nathan Congdon, MD, MPH 


\begin{abstract}
Purpose: To study the effect of free glasses combined with teacher incentives on inschool glasses wear among Chinese urban migrant children.

Design: Cluster-randomized controlled trial.

Methods: Children with VA $<=6 / 12$ in either eye due to refractive error in 94 randomlychosen primary schools underwent randomization by school to receive free glasses, education on their use and a teacher incentive (Intervention), or glasses prescriptions only (Control). Intervention group teachers received a tablet computer if $>=80 \%$ of children given glasses wore them during un-announced visits 6 weeks and 6 months (main outcome) after intervention.

Results: Among 4376 children, 728 (16.7\%, mean age 10.9 years, $51.0 \%$ boys) met enrollment criteria and were randomly allocated, 358 (49.2\%, 47 schools) to Intervention and 370 (50.8\%, 47 schools) to Control. Among these, 693 children (95.2\%) completed the study and underwent analysis. Spectacle wear was significantly higher at 6 months among Intervention children (Observed [main outcome]: $68.3 \%$ versus 23.9\%, Adjusted Odds Ratio $[\mathrm{OR}]=11.5,95 \%$ Confidence Interval [CI] 5.91-22.5, P<0.001; Self-reported: $90.6 \%$ versus $32.1 \%, \mathrm{OR}=43.7,95 \% \mathrm{CI}=21.7-88.5, \mathrm{P}<0.001)$. Other predictors of observed wear at 6 months included baseline spectacle wear $(\mathrm{P}<0.001)$, uncorrected $\mathrm{VA}<6 / 18(\mathrm{P}=0.01)$ and parental spectacle wear $(\mathrm{P}=0.02)$. The 6-month observed wear rate was only $41 \%$ among similar-aged children provided free glasses in our previous trial without teacher incentives.

Conclusions: Free spectacles and teacher incentives maintain classroom wear in the large majority of children needing glasses over a school year. Low wear among Control children demonstrates the need for interventions.
\end{abstract}


1. It is unfortunate that it didn't have the power to include the third and more interesting control group (free glasses without intervention), and it begs the question why the authors chose the control group that they did, rather than the free glasses control group? Even though it is a reasonably sized cluster RCT the numbers were smaller than the authors' previous cited paper demonstrating approximately $40 \%$ observed glasses wear at 6 months with free glasses. Therefore even though the primary outcome of $68 \%$ in the intervention group is likely better (and better than what has been reported), it may represent a different population in terms of unmeasured confounders and can't be directly compared. It would have been more interesting, I would think, to compare the intervention group to what they had already proven worked better than not providing glasses... The authors do acknowledge this limitation but don't really explain why they chose the "Rx only no glasses" control group, which makes the difference between their primary outcome in intervention and control less interesting (though still high enough to be reported on its own merit)

Response: As the reviewer suggests, the authors found ourselves in the position of having to eliminate one of the groups in the study. We fully agree that having a "partial control" who received only free glasses but no incentive would have been intellectually interesting, and would naturally have made it easier to isolate the impact of the teacher incentive itself. However, our primary interest was to be able to measure the impact of the combined intervention, of free glasses+incentive. Without a "pure control," this would not have been possible. The authors are principally interested in studying interventions which are relevant to actual programs and policy, and we feel it is unlikely that a teacher incentive intervention would be used without providing free glasses at the same time, so isolating the impact of the incentive by itself was slightly less important to us. We had already studied the impact of free glasses alone in other settings, and found it to be less than ideal. The smaller-than-expected number of schools put us in the difficult position of having to make a compromise; the result was, as we acknowledge, less than ideal. But we do feel comfortable with the choice we made to retain the pure control group.

2. The authors state that 29/47 (more than half of the ) schools in the intervention group met or exceeded the $80 \%$ bar at both study visits, but the overall observed rate was only $68 \%$, suggesting there was at least moderate variation. It may be interesting to know a little more about the distribution in the group (or it may not); was it bimodal with the "responders" > 80\% and the "non-responders" $<<60 \%$ or was it relatively continuous? If there is a cluster in the control group response range (or in the free glasses historical control group response range) it would be interesting to figure out why those classes responded differently.

Response: In the first place, our statistician apologizes that the correct number of schools meeting the standard of $80 \%$ of children needing glasses wearing them should be $19 / 47=40.4 \%$. The authors provide the below figure showing the wear rates at the various schools stratified by study group assignment. Power in these cluster randomized 
studies is driven principally by the number of schools, rather than the number of students at each school. For this reason, we had little practical motivation to increase the number of children at each school, and many schools had only a modest number of enrolled children, mean 7.7 (SD 4.1) overall, 7.6 (3.8) in Intervention schools and 7.9 (4.4 in Control ones). For this reason, it may be difficult to draw useful conclusions about the impact of school-level factors on wear rates, which would presumably be the reason for performing this analysis. In view of this, we would not plan to include this figure in the table, unless the reviewers and editor were strongly in favour.

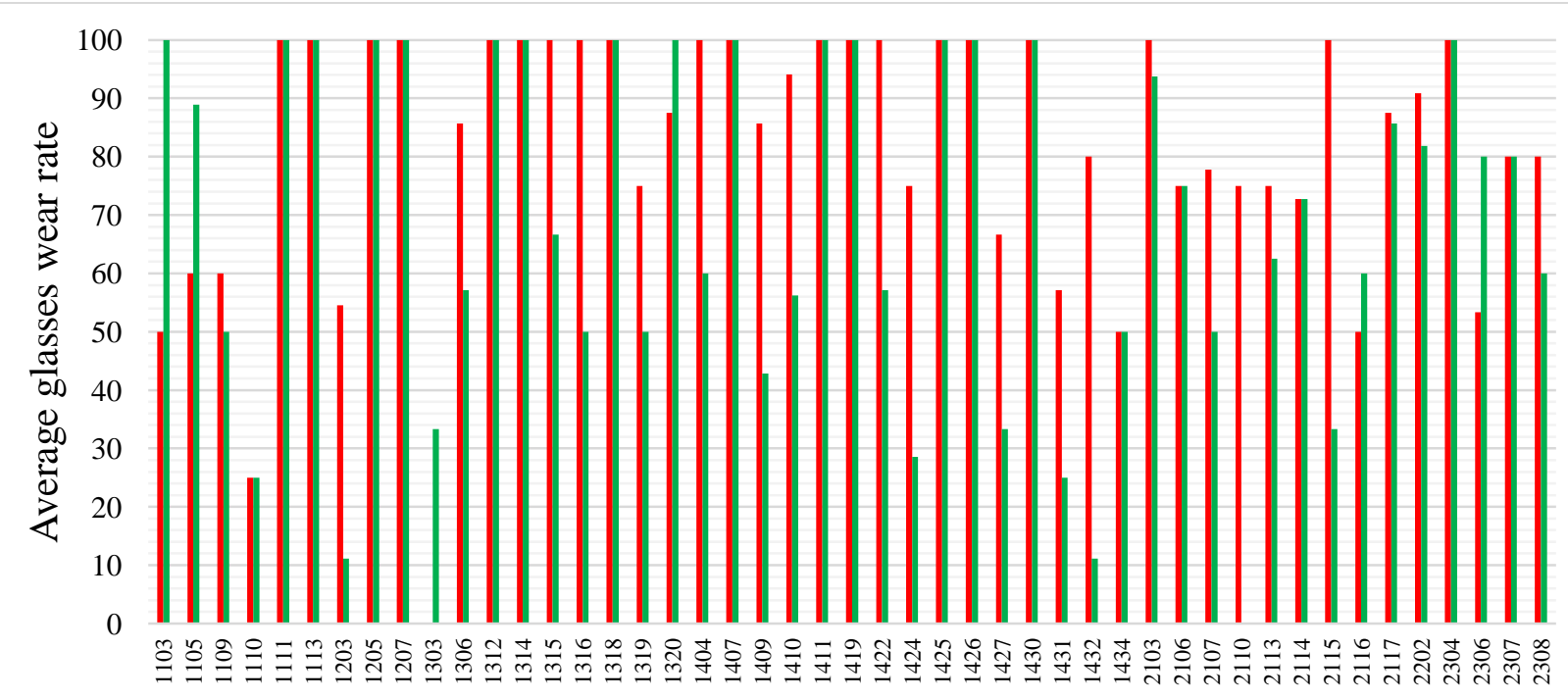

- Six week follow-up $\quad$ Six month follow-up

Figure 1 Average glasses wear rate at six week and six month follow-ups among intervention schools

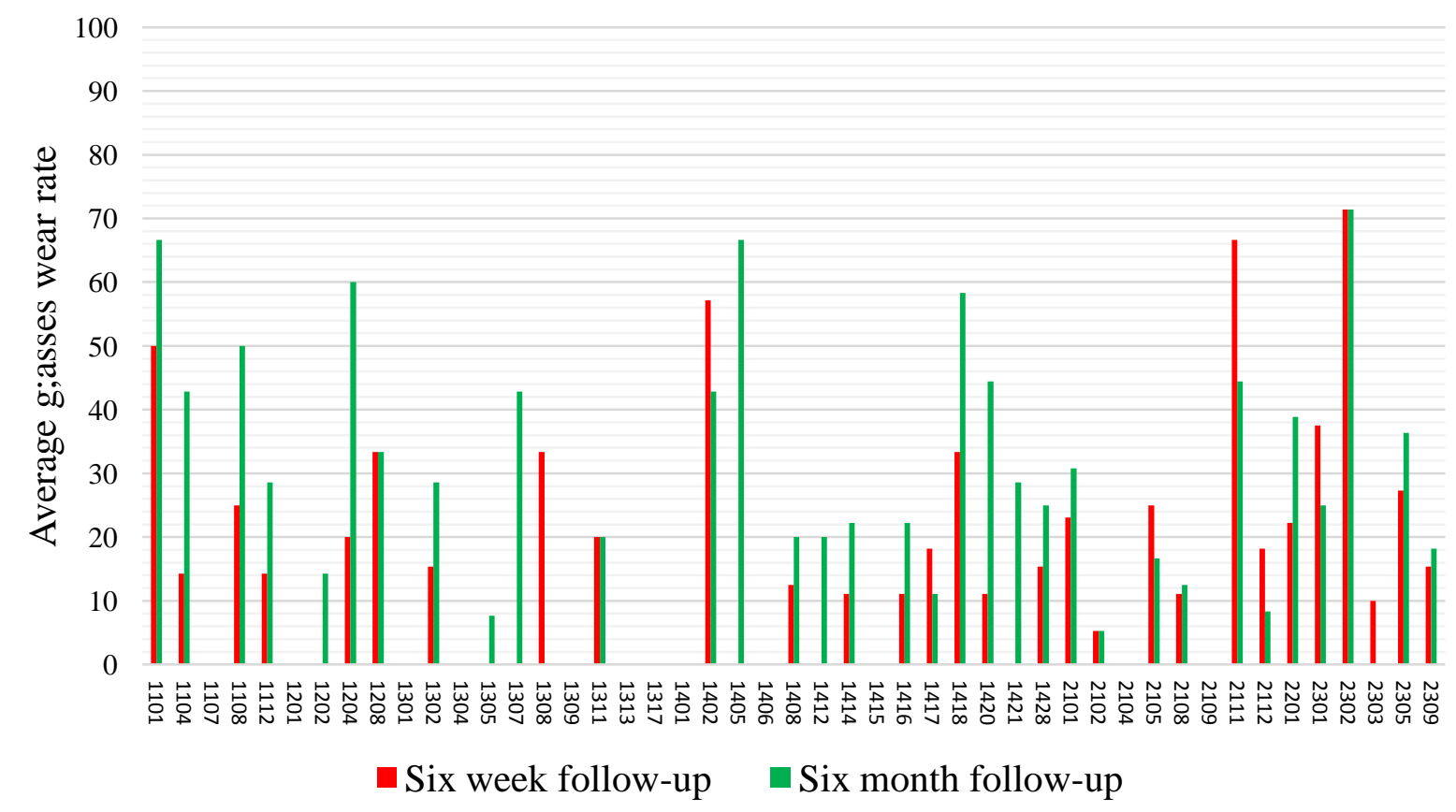


Figure 2 Average glasses wear rate at six week and six month follow-ups among control schools

3. It would be nice if the authors could comment as to the value of the incentive (the tablet computer) in this context? i.e. how much is this tablet worth vs. weekly/monthly salary, etc, to get an appropriate context for any future work in this area.

Response: The tablet that we gave in our teacher incentive project cost around USD350. The monthly salary of a teacher in the project schools was around USD475 USD. This means the incentive was a bit less than one month salary. This information has been added to the Methods.

4. The abstract and introduction section are both clearly and very well written. The only important aspect missing from the abstract, introduction and first sentence of the discussion was that the intervention presented in this paper also included an educational session to promote the use of glasses.

Response: The authors thank the reviewer for pointing out this omission, which has now been corrected in the Abstract, Introduction and Discussion.

5. Methods: Perhaps a non-bulleted description of the eligibility criteria and randomization groups in paragraph format would be preferred. Please clarify if it was necessary to meet both inclusion criteria?

Response: We agree that it is important to clarify that both major eligibility criteria (vision and refraction) had to be met, but find that the use of bulleting seems to make it easier to get this across, particularly as it allows us to clearly set out two criteria, with the specific power cutoffs being subsidiary to the second of these. The authors are concerned this might be less clear without bullets:

All children in the selected classes meeting both the following visual and refractive criteria were eligible:

- Uncorrected visual acuity $<=6 / 12$ in either eye

- Refractive error meeting cutoffs shown to be associated with significantly greater improvement in visual acuity when corrected. ${ }^{16}$

○ Myopia $<=-0.75$ diopters $(D)$

- Hyperopia $>=+2.00 \mathrm{D}$ or

- Astigmatism (Non-spherical refractive error) $>=1.00 \mathrm{D}$

6. In the Statistical Methods section, self-reported wear at follow-up was defined as wearing glasses "Always" or "Only for studying" so it is unclear how the "usually not worn" 
category was handled. Please clarify if the "Always" and "Only for studying" responses were combined to indicate wear or if those who wore glasses always were compared to those who did not.

Response: We have now clarified that "Always" and "Only for studying" were taken together to constitute a positive response. The reason for this is that the authors feel classroom wear is most significant for children, in view of recent evidence of the educational impact of wearing glasses: "a positive self-report of wear at follow-up was defined as wearing glasses "Always" or "Only for studying.","

7. How was 'wearing the glasses' during the unannounced visit defined specifically? Did the child just need to have their glasses with them at the time or did they need to have the glasses on their face when the assessment team arrived?

Response: By "observed wear", we mean exactly this, the glasses had to be worn on the child's face. We have clarified this now in the Methods.

8. Please indicate if the self-reported spectacle use reported at the same time/day as the direct observation/examination.

Response: We have clarified that these two assessments were made on the same occasion.

9. What was the retail value of the tablet computer in USD?

Response: Please see our response to \#3 above.

10. Are these children assigned to a single teacher throughout the whole day for all of their classes? How many teachers or classrooms were involved at each school?

Response: Chinese, Mathematics, and English are the main academic subjects in Chinese primary schools. Children often had separate teachers for Chinese, Mathematics and English, and three classrooms would be involved over the course of a typical school week. In the intervention schools, the incentive was offered to Chinese, Mathematics, and English teachers. This means that in most schools, three teachers were involved. This has been clarified now in the text.

11. Did the authors consider using a multilevel model with clustering by classroom, in addition to school?

Response: We avoided clustering at this level by choosing only one class at each school. Thus, within-class and within school clustering would have been the same for our sample. 
12. Is it surprising and upsetting that the study design excluded children whose VA was not correctable to $>=6 / 12$ in both eyes, as I would expect that some of these children with low vision may have benefitted visually from wearing glasses even if they were not fully correctable. Please comment on this limitation.

Response: The reviewer raises an important point. The focus of this project was on research rather than service delivery, and the authors felt, based on our program experience, that children for whom glasses wear did not yield optimal visual acuity would be much less likely to wear their spectacles, even in the face of interventions. Thus they would not constitute an ideal group in which to test the efficacy of interventions designed to increase wear.

13. The last paragraph on page 8 referencing factors that may affect observed wear, it is unclear what 'both parents working in the area' refers to and how it may affect wear. Does it mean that both parents would need to be employed in the local community and what are the potential implications of that situation? The multivariate $\mathrm{p}$-value for this variable was $\mathrm{p}=0.09$ and it is highlighted as being statistically significant although it is $>0.05$; is this an error?

Response: The authors thank the reviewer for pointing out the mistaken highlighting, which has been corrected. This population of urban migrants is inherently unstable, with family members routinely moving back and forth to their rural village of origin. We hypothesized that the absence of one or more parents from the home might impact on a family's ability to purchase spectacles, and then to support a child in their regular use. This question has been clarified in the Questionnaire section of the Methods.

14. Discussion. The second and third paragraphs of the discussion should be combined and the background info on their review of the literature (in the 2nd paragraph) could be potentially written more concisely.

Response: We have eliminated details about our literature review, which the reviewer and editor are welcome to add back in as they see fit.

15. It would be helpful to elaborate on the issue of a quarter of parents who declined cycloplegic refraction. Do the authors believe that these parents would have consented to refraction without cycloplegia to increase the rates of children who had their spectacle Rx determined? Or is the issue that the parents were against glasses since they thought that they made vision worse (I believe they have that data from the child's perspective) and did not want their child evaluated at all? The authors should indicate that interventional research providing parental education on this topic is an important area of future study to attempt to increase glasses wear.

Response: There are several important points here: 
- The authors' impression from this and previous research and service delivery projects in China is that the parents' refusal was specific to cycloplegia.

Resistance to cycloplegia for children is quite widespread in China, and seems to revolve both around a concern that impaired accommodation will disrupt a child's studies as well as the feeling (perhaps based on cases of angle closure in older adults precipitated by pharmacologic dilation of the pupil) that cycloplegia itself may be dangerous.

- Regarding educational interventions: the authors have published two RCTs on educational interventions designed to increase uptake of spectacles. The first of these (Congdon et al, Ophthalmology, 2011) included children and teachers but not parents, and found no effect of the intervention. The second (Ma et al, BMJ, 2014) did include parents as well as children and teachers, and found an effect that was statistically significant, but only a fraction of the effect of providing free glasses in the same trial. Because the topic is somewhat complicated and not directly relevant to the main focus of the paper, we have not added this to the Discussion, but the conclusion of the authors would be that educational interventions alone are probably not as effective in promoting wear as is the provision of free spectacles and teacher-focused incentives.

16. Perhaps the authors could discuss their rationale for including 5th grade children and how well is this intervention might be anticipated to work in children who are either younger or older than the current study population?

Response: We usually avoid enrolling $1^{\text {st }}, 2^{\text {nd }}$ or $6^{\text {th }}$ grade children in our school-based projects, the former two because they are too young to comply with our questionnaires and prevalence rates of myopia are low, and the latter because their academic load is unusually heavy due to preparation for middle school entry examinations, and thus schools will not usually allow any potential disruption to their schedule. We could have equally well chosen $3 \mathrm{rd}, 4^{\text {th }}$ or $5^{\text {th }}$ grade children, but elected to enrol $5^{\text {th }}$ graders as their RE prevalence is expected to be the highest. We have not usually found important differences between $3^{\text {rd }}, 4^{\text {th }}$ and 5 th graders in our studies, and would not expect the response to teacher incentives to differ greatly. However, we have added a line to the limitations section indicating that our results can only be applied with caution to older and younger children.

17. In the last paragraph of the discussion, the authors should address another aspect in the long-term sustainability of this specific intervention approach to continue to sustain teacher motivation to promote glasses wear beyond the first year of participation. When a new class year begins, the teacher incentive may need to be something other than a tablet computer, but a similar item, since they may not need a new tablet every year. In addition, future research should elucidate if there were any factors that significantly predicted teachers who did not achieve the $80 \%$ compliance level. 
Response: In our latest studies, we are examining incentives based on teachers' evaluations, which can impact salary, as a more sustainable alternative to incentive gifts. This has been indicated in the Discussion as requested.

18. Page 3, Line 18: It is unclear to me what you are referring to when you use the word symptoms here. Do you mean lack of symptoms?

Response: We have changed the word from "symptoms" to "discomfort."

19. Page 4, Line 41: The criteria you used for decision to prescribe glasses is quite low compared with consensus based studies in the US regarding threshold for glasses need. Could the need for such extreme intervention such as teacher incentives be the result of the fact that the glasses were of such low value to many children that the children themselves did not receive a significant benefit from the glasses, hence were not inclined to wear them? The inclusion of information on the severity of refractive errors treated would be useful.

Response: These cutoffs are based on both evidence and convention. There are several pieces of evidence suggesting that these criteria are reasonable:

- As we cite in the manuscript, our previous study (Congdon et al, BJO, 2008) in S Africa indicated that the refractive power cutoffs we chose were associated with significantly increased odds of improved vision.

- Our study in Mexican school children (Esteso et al, IOVS, 2007) demonstrated significantly improved self-reported visual function when RE at these visual acuity levels was corrected.

- Our recent RCT (Me at al, BMJ, 2014) demonstrated significant educational gains when refractive error associated with visual acuity at this level was corrected.

- Finally, these VA cutoffs have become fairly standard in studies of RE among children, as a result of their use in the RESC studies.

While it is generally true that rates of wear are higher among children with worse uncorrected VA, we have found (Ma et al, BMJ, 2014; Li et al IOVS 2008)) that a large proportion of children are without glasses even at much worse levels of uncorrected VA in rural China, suggesting the need for interventions such as the one tested in the current MS regardless of how cutoffs are set.

20. "Trial registration information: Registration site: http://isrctn.org Registration number: ISRCTN1672006" belongs in the Methods section and not the title page. 


\section{Response: This has been corrected.}

21. Acknowledgment section should conform to sections A-C instructions.

\section{Response: This has been modified.}

22. Your references are not in the required AMA reference format. Journal issue numbers required.

\section{Response: These have been added.}

23. All figure and table titles need to be enhanced so that the reader can understand each figure and table independent of the manuscript text (as a stand alone). eg include children with refractive error in each title OR something similar.

\section{Response: This has now been done.}

24. For each revision, the corresponding author must provide a statement that each of the coauthors has seen and agrees with each of the changes made to this manuscript in the revision and to the way his or her name is listed. It is not appropriate to add or remove authors at any time. Authors should list only their institutional affiliation at the place that they participated in the research; a footnote on the title page can clarify if any of the authors is now at a different location. The footnote should also contain the full address and phone number, including email address, of the one corresponding author.

Response: Each of the coauthors has seen and agrees with each of the changes made to this manuscript in the revision and to the way his or her name is listed. Listing of affiliations follows journal policy.

25. Correspondence between the author and the journal or future readers is crucial to advancing or questioning the science on your topic. The email address for future correspondence must be accurate for at least a year following acceptance; the corresponding author (and email address) for this article should be the same in the AJO submission system and on the article title page.

\section{Response: We have followed this policy.}

26. Please ensure that all files intended for final publication are submitted to the office with each revision. If your final revision does not include all necessary files, those files will not be transmitted for publication. A common, and unacceptable, deficiency of many submissions is failure to refer to (call out) each figure, table and reference in the text. Please confirm that you have checked this function. 


\section{Response: We have checked this.}

27. Only one abstract should appear in your submission. Please make sure the corrected abstract is uploaded separately from the text and remove any extra copies of the abstract from the manuscript file. Please correct the Abstract if meaningful changes were made in the text during revision process.

Response: Only one copy, of the corrected Abstract as a separate file, has been uploaded.

28. The title page should also contain a suggested "short title" (limited to 60 characters including spaces) for your manuscript that will be included as a footnote in the printed version. The "short title" should have no abbreviations or use ONLY abbreviations well known to all ophthalmologists. See the print journal for examples.

\section{Response: This is provided.}

29. Authors must identify each uploaded file completely and properly. Eg a file should be labeled as Figure1upper right.tiff OR BiosketchJones.doc,OR PhotoDrJones.jpg, etc. It is not satisfactory to label incompletely as Biosktch.doc or AuthorPhoto.jpg since the copyeditors cannot confirm appropriate file identification.

\section{Response: We follow this requirement in file naming.}

30. The Journal requires that Clinical Trials be registered and the Methods Section should contain a statement about the registration location and number. Satisfactory public databases include the National Institute of Health maintained site at http://www.clinicaltrials.gov (for either NIH or non-NIH sponsored studies) or the International Standard Randomized Controlled Trials at http://www.controlled-trials.com.

\section{Response: This statement has been moved as requested above to the Methods.}

31. The first paragraph of the Methods Section should describe both the specific study design (see AJO.com for glossary of descriptive terms) and, for human studies, a statement about Institutional Review Board (or similar body) approval and the Informed Consent approval. Name the IRB that approved the research or provide a statement and rationale as to why the named IRB waived approval. Provide precise information about what they approved prospectively and retrospectively. If this is a systematic evaluation of a treatment or a device ("research"), then IRB approval is required usually in a prospective manner. The AJO will not publish research on humans that does not have IRB approval. For clarification, see: http://www.ijo.in/text.asp?2007/55/1/1/29486. Confirm proper informed consent for both the treatment and/or participation in the research, HIPAA compliance, Clinical Trials registration (number and location), and Institutional Animal Care and Use Committee guidelines if the study involved animals. If the IRB waived the need for approval of this research, then indicate adherence to the Declaration of Helsinki and all federal or state laws in your country. 
Authors cannot make the decision as to whether IRB approval is needed; your IRB should make that decision and provide a waiver if they feel it does not require IRB approval.

Response: We have modified our first paragraph in the Methods to comply with these requirements. It is not clear from the above if you want the Declaration of Helsinki statement even if IRB approval was sought and granted; following convention, we have left it in.

32. The AJO requires enhanced disclosure information from the authors in a specific format. The following information should appear, in the order indicated (labeled A. through C.), in the Acknowledgement Section of the manuscript (just prior to the References). The information will appear in the print journal. This information should not appear on the Title page of the manuscript or in the Methods section of the manuscript. Authors are referred to Editorials that provide more explanation regarding this Acknowledgment Section: Toward Transparency of Financial Disclosure (http://www.ajo.com/article/S0002-9394(14)00578-9/fulltext) and Footnotes, Acknowledgments, and Authorship: Toward Greater Responsibility, Accountability, and Transparency (http://www.ajo.com/article/S0002-9394(14)00577-7/fulltext)

a. Funding/Support: any government and non-government support must be acknowledged. The authors are reminded that several governments require providing open access to your manuscript. If there is funding, the authors must attest to their independence in reporting the study data and interpretation of the data. If no funding, please state "none". Provide location of all grantors.

b. Financial Disclosures: The Disclosures should summarize all the information contained in the ICMJE Financial Disclosure Forms for all authors. This journal specifically requests that you state in this section all your financial disclosures in medicine, i.e. we do not wish the authors to try to judge if any of these disclosures might relate to this manuscript. If an author has no financial disclosures in medicine, then state "none." Provide location of all commercial companies.

c. Other Acknowledgments: Statisticians and medical writers or industry writers might fulfill the criteria for authorship and should be recognized in that role. Otherwise recognize statistical consultation, medical writers or industry writers in the acknowledgment section here. Include the name and affiliation of the individual. Editorial assistants, photographers, artists, laboratory associates, and others who simply assist in preparation of a manuscript are not to be acknowledged, however valuable their service. The Editor-in-Chief will permit limited exceptions. Because readers may infer endorsement of the data and conclusions, all persons must have given permission to be acknowledged and this must be confirmed in the cover letter.

\section{Response: We have modified our disclosure and funding material to meet these requirements.}

33. Minimum figure requirements are 300 dpi resolution and at least 3.5 inches wide per 
figure part/file submitted. Maximum individual file size is $12 \mathrm{MB}$. Only TIFF, JPEG, and EPS are allowable formats for photos. Word is permitted for graphs ONLY IF the graph was created in Word; no figure should be pasted into Word. Please also use smooth/crisp fonts such as Arial in the creation of your figure to ensure readability. Figure number (Figure 1, Figure 2 Right, etc.) should not be on the figure itself.

Our system has an Artwork Quality Check function that will check your figures at the time of revision. Once the File Upload page is complete, click Next to run Artwork QC, which will provide results according to our print-quality guidelines. Simply click on the results to obtain feedback for any shortcomings. However, the AJO standards for art as listed above and in the Author Instructions at AJO.com exceed those of this tool and the authors are required to adhere to AJO standards, despite assurances from this Artwork Quality Check of a "Pass." "Pass with Warning" is not accepted. Please make all improvements prior to resubmission.

\section{Response: Our figure was originally created in Word.}

34. For multi-part figures, each part of the figure should be submitted individually at the correct resolution and file type. Each part must be named according to the location in which it is placed (i.e., 1 Top Right, 2 Middle Left, etc.) and NOT by letter (i.e., 1A, 2B). Do not put labels such as A, B, C on the figures. You may additionally submit a composite figure in Word for complex figures to indicate how you would wish the individual figure parts to be arranged upon publication. Please note that due to space restrictions, the publisher may not be able to use the provided layout, so it is imperative to also include any arrows, markings, and labels on the original figures as well. Alternatively, you may submit a composite figure only at the correct resolution and file type above with any appropriate arrows, markings, or labels, though the publisher may later request individual files if space does not permit use of the collage and publication could be delayed as a result.

\section{Response: We have no multi-part figures.}

35. If your manuscript was submitted with color figures, it is expected that the authors will pay for the color art that appears in the print issue. It is not appropriate to switch to black and white figures during a revision stage or post-acceptance if the manuscript was peer reviewed with color figures. The Editor in Chief reserves the right to decide if Black and White figures are more appropriate in place of any color figures and that decision is made at the initial revision request. See Author Information at AJO.com for more specific details concerning the costs.

\section{Response: We have no color figures.}

36. REFERENCES: PLEASE NOTE that the AJO style is identical to the AMA style and lists the first 6 authors; if more than 6, then list the first 3 and then "et al." Current AMA style requires journal issue numbers and journal abbreviations in italics. More information about 
AJO references is available in Author Information at AJO.com. The authors are SOLELY responsible for correct references; this service is not provided by the Journal copyeditors.

\section{Response: We have modified our references to match this format.}

37. The Corresponding Author is requested to provide a Table of Contents Statement (up to 75 words in length) that presents the content and clinical implications of the article for the Table of Contents of the Journal (see print copy of AJO). This statement should be on a separate page that contains the manuscript title and manuscript number. This is a stand-alone document from the manuscript and as such should not contain abbreviations or first-person pronouns (I, we).

\section{Response: This has been submitted.}

38. Please confirm that your Discussion Section adheres to the following Author Information at AJO.com as appropriate for your manuscript: "Elucidate (but do not reiterate) the results, identify any statistically or clinically significant limitations or qualifications of the study, provide responses to other and contradictory literature, and state the conclusions that are directly supported by the data. Excessive generalization and undue speculation should be avoided. Give equal emphasis to positive and negative findings, state whether and what additional study is required, and conclude with the clinical applications or implications supported by the study. The conclusions are incorporated into the end of the discussion. Authors should avoid making statements on economic benefits and costs unless their manuscript includes economic data and analyses. Do not allude to work that has not been completed."

\section{Response: The authors believe that our Discussion section meets these requirements.}

39. AJO.com offers the opportunity to present additional data that cannot be published in the print issue, including additional illustrations and tables, videotapes of procedures, and animations. Supplemental Material must be submitted at the time of revision according to specifications, and such material may be edited.

Instructions for preparing supplemental material are listed at www.ajo.com/authorinfo under the "Accepted Manuscripts" sections. When uploading your supplemental material on the Attach Files page, please choose Multimedia Supplementary Materials for all parts and label each part (eg., Supplemental Figure Legend, Supplemental Figure 1, Supplemental video etc.). The legend for all Supplemental Material should also be uploaded as Multimedia Supplementary Materials. Each figure legend or table title must contain enough information so as to be able to be understood independent of the manuscript text (stand alone). If you are including supplemental material with your submission, please note the following on your manuscript title page: "Supplemental Material available at AJO.com" and also note, at the 
appropriate location in the manuscript and in parenthesis, "(Supplemental Material at AJO.com or Supplemental Figure 1)".

Once the article is accepted, the Supplemental Material will be forwarded by the AJO office to Dr Kaiser, the AJO Associate Editor supervising the Supplemental Material at AJO.com. You will be notified of its acceptance or requests for revisions.

\section{Response: We have no supplemental material to submit.}

40. The AJO seeks to further enhance recognition for the contributors of the scientific content in the Journal. Please provide a biographic sketch (limited to 75 words and one paragraph) from the first author (or both authors if there are only two) and a digital photo to be placed on the web site linked with the online version at www.ajo.com. Biosketches and biophotos should be uploaded individually.

The digital photo should adhere to the following specifications:

Size - minimum 325 pixels by 500 pixels

Resolution -300 dpi

File format - .gif or .jpg

Head \& shoulders in a professional setting

There is no additional charge for color biophotos.

Please note that the AQC system checks biophotos to provide feedback but these photos do not necessarily have to 'Pass' as long as they adhere to the minimum requirement above.

If there are more than two authors on the paper, the first photo and biosketch should be the first author and the second photo and biosketch should be determined by collective author agreement. Examples can be found on our Editorial Board page at http://www.ajo.com/content/ed_board_bios. Please do not use outline format and do not use abbreviations. Include affiliations and the author's primary research interests. Upload these items into Editorial Manager under the appropriate heading along with your revised manuscript.

** If you will be submitting a Biosketch and/or photo, it must be done at the time of revision.

\section{Response: This has been submitted on behalf of our first author, Prof Hongmei Yi.}

41. With revision, please provide a letter outlining your responses to each of these numbered items. You may copy and paste these comments into the Reviewer Response box during the revision upload process. Each of your responses should be given a number corresponding to the above items for ease of reference. Also identify the page number and line in your revision where changes can be found.

Revision marks must be removed from manuscript, all changes accepted, and Track Changes turned off. Submit only a clean copy of the manuscript. 
SUBMITTING REVISION: Submit your revision to the system available at http://ees.elsevier.com/ajo .

A tutorial for uploading is available under "Author Tutorial."

DECLINING REVISION: If you do not plan to submit a revision, or wish to submit your manuscript elsewhere, please reply to this email with your intentions to withdraw your manuscript from consideration.

While no commitment can be made at this time, acceptance for publication is anticipated after review of a revised manuscript conforming to the recommendations for revision. If the authors persist with formatting errors, however, the manuscript will be rejected.

Response: Done as requested. 
1. Please remove tracked changes as supplementary material. Provide only the clean publication ready manuscript.

Response: This has been done.

2. Tables should be uploaded individually.

Response: This has now been done

3. Figure should be rotated so that reviewers can read it.

Response: This has been done.

4. Figure title should be more specific about which "study' this is. i.e. we are not able to understand the figure independent of the manuscript text.

Response: The title has been amended to: "Flowchart for enrollment and allocation of children with refractive error in a randomized trial of free glasses and teacher incentives to promote spectacle wear" 
Impact of Free Glasses and a Teacher Incentive on Children's Use of Eyeglasses: A Cluster-Randomized Controlled Trial

${ }^{1}$ Hongmei Yi, ${ }^{2}$ Haiqing Zhang, ${ }^{3,}{ }^{4}$ Xiaochen Ma, ${ }^{1}$ Linxiu Zhang, ${ }^{5,}{ }^{6}$ Xiuqin Wang, ${ }^{5}$ Ling Jin, ${ }^{7,8}$ Kovin Naidoo, ${ }^{7}$ Hasan Minto, ${ }^{9}$ Haidong Zou, ${ }^{9}$ Lina Lu, ${ }^{3}$ Scott Rozelle, ${ }^{5,10,}$

${ }^{11}$ Nathan Congdon

1. Center for Chinese Agricultural Policy, Institute of Geographical Sciences and Natural Resources Research, Chinese Academy of Sciences, Beijing, Beijing, China.

2. College of Economics and Management, Shanghai Ocean University, Shanghai, China.

3. China Center for Health Development Studies, Peking University, Beijing, China

4. Stanford Center for International Development, Stanford University, Stanford, CA, United States.

5. State Key Laboratory of Ophthalmology and Division of Preventive Ophthalmology, Zhongshan Ophthalmic Center, Sun Yat-sen University, Guangzhou, China.

6. Affiliated Hospital of Guangdong Medical College, Zhanjiang, China

7. Brien Holden Vision Institute, Durban, South Africa.

8. AVRI, University of KwaZulu-Natal, Durban, South Africa

9. Shanghai Eye Disease Prevention and Treatment Center, Shanghai, China.

10. ORBIS International, New York, NY, United States.

11. Queen's University Belfast, Belfast UK.

Address for correspondence: Prof Nathan Congdon, ncongdon1 @ gmail.com; Translational Research for Equitable Eyecare (TREE), Zhongshan Ophthalmic Center, Sun Yat-sen University, Xianlie S Rd \#54, Guangzhou China 510060

Short title: Randomized trial: increasing children's glasses use

Key words: Myopia, children, eyeglasses, China, migrant, compliance, teacher incentive Manuscript length: Text 3445 words, 1 Figure, 4 tables Abstract: 250 words

Draft: 3 August 2015 
Introduction

Uncorrected refractive error is the leading cause of visual disability among children worldwide, affecting nearly 13 million under the age of 16 years, among whom nearly half live in China. ${ }^{1}$ If not treated, refractive error is associated with loss of visual function $^{2}$ and reduced educational performance in children. ${ }^{3}$ Though refractive error can be safely ${ }^{4}$ and inexpensively managed with glasses, as few as one in six children needing spectacles have them in rural parts of the developing world. ${ }^{3}$

Spectacle distribution programs for children can lead to normalization of visual function $^{5}$ and trial-proven, significant improvements in educational outcomes. ${ }^{3}$ However, programs in China, ${ }^{3}$ Mexico ${ }^{6}$ and Africa ${ }^{7}$ have reported poor compliance with free spectacles, with rates of observed, short-term wear at unannounced visits ranging from $13 \%$ to $41 \%$. Factors limiting wear of glasses include discomfort or inconvenience, ${ }^{6,8}$ concerns over being teased, ${ }^{6,9}$ parental opposition, ${ }^{6,10-11}$ lack of perceived need ${ }^{6,8-10}$ and fear of damage to the eyes ${ }^{8-11}$ (though a trial ${ }^{4}$ has now demonstrated that spectacle wear is in fact protective against age-related declines in uncorrected visual acuity among children). Previous randomized trials of specially-designed educational interventions promoting spectacle wear aimed at children teachers and parents have demonstrated very modest $^{3}$ or no ${ }^{12}$ impact on observed use of glasses among children at un-announced follow-up visits.

We carried out a cluster-randomized controlled trial among children at predominantly migrant schools in urban eastern China, to determine whether providing free glasses combined with education on their use and a teacher incentive could lead to improvements in observed spectacle wear among children at un-announced visits over the course of a school year. Comparison is also made in the current report to rates of observed wear over similar time periods among similar-aged children receiving free spectacles under an identical protocol in a previous published trial, ${ }^{3}$ without the use of teacher incentives. Our hypothesis was that the combination of free spectacles and teacher incentives would maintain compliance with classroom spectacle wear, where impact on educational attainment is presumably greatest, in the majority of Incentive group children over the course of a school year. 
Methods

The protocol for this cluster-randomized trial was prospectively approved in full by Institutional Review Boards at Stanford University (Palo Alto, USA) and the Zhongshan Ophthalmic Center (Guangzhou, China). Permission was received from local Boards of Education in each setting, and the principals of all schools, and at least one parent provided written informed consent for the participation of each child. The principles of the Declaration of Helsinki were followed throughout. This trial was registered at http://isrctn.org, under the registration number: ISRCTN16720066.

\section{Setting}

The study was carried out in Shanghai (the world's largest city, with a total municipal population of 24.2 million in 2012, including 9.6 million migrants) ${ }^{13}$ and Suzhou/Wuxi ("twin cities" located near Shanghai with a combined prefectural population of 17.0 million in 2014 , half estimated to be migrants). ${ }^{14}$ These cities were selected for having among China's largest populations of migrants, a term defined in this study as including families who did not have a local primary residence (hukou), implying reduced access to local public healthcare and schools. Substantial rural and suburban areas exist within the borders of all of these cities, and migrant populations tend to be clustered in these rural/suburban zones. In these communities migrant children mostly attend schools that are private and unregulated, with little support from the government. ${ }^{15}$

\section{Sampling and eligibility criteria}

All elementary schools in these cities identified by the local Bureaus of Education as having a primarily migrant population were enumerated and 94 schools were selected at random (66 in Shanghai and 28 in Suzhou/Wuxi). One 5th grade class (children aged 10-12 years) was selected at random in each school, and questionnaires (see below) were administered and visual acuity testing and refraction (see below) carried out. All children in the selected classes meeting both the following visual and refractive criteria were eligible:

- Uncorrected visual acuity $<=6 / 12$ in either eye

- Refractive error meeting cutoffs shown to be associated with significantly greater improvement in visual acuity when corrected. ${ }^{16}$

○ Myopia $<=-0.75$ diopters (D)

○ Hyperopia $>=+2.00 \mathrm{D}$ or

○ Astigmatism (Non-spherical refractive error) $>=1.00 \mathrm{D}$

\section{Questionnaires}

At baseline (September 2013, beginning of the school year), enumerators administered questionnaires to children concerning their age, sex, urban versus rural residence, whether they were an only child, glasses wear, belief that wearing glasses harms vision (a common misapprehension in China), ${ }^{8,10}$ family migrant status, parental glasses wear, education and place of residence/work (local versus elsewhere). A studyspecific mathematics test was administered as an index of academic achievement. 
Teachers were asked to state whether the blackboard (potentially not clearly seen by myopic children and so a possible driver of glasses use) was used for all, most, about half, little or none of teaching. A parental questionnaire asked about ownership of 14 selected items as an index of family wealth. Children were told to bring their spectacles on the day of the baseline examination, and baseline spectacle use was defined as being able to produce glasses at school.

\section{Visual Acuity Assessment}

Children underwent baseline visual acuity screening at school by a nurse and trained assistant. Visual acuity was tested separately for each eye without refraction at 4 meters using Early Treatment Diabetic Retinopathy Study ${ }^{17}$ chart (Precision Vision, La Salle, IL, USA) in a well-lighted, indoor area. If the orientation of at least four of five optotypes on the 6/60 line was correctly identified, children were examined on the 6/30 line, $6 / 15$ and then line by line to $6 / 3$. Visual acuity for an eye was defined as the lowest line on which 4 of 5 optotypes were read correctly. If the top line could not be read at 4 meters, the subject was tested as above at 1 meter, and the measured visual acuity was divided by 4 .

\section{Refraction}

Children with uncorrected visual acuity $<=6 / 12$ in either eye underwent cycloplegia with up to three drops each of cyclopentolate $1 \%$ and proparacaine hydrochloride $0.5 \%$. Children then underwent automated refraction (Topcon KR 8900, Tokyo, Japan) with subjective refinement by a local optometrist, previously trained by experienced optometrists from Zhongshan Ophthalmic Center.

\section{Randomization and Interventions (Figure 1)}

This was a cluster-randomized, controlled trial, with schools as the clusters. The trial was originally designed to include 150 schools, and to include three treatment arms (control, free glasses, and free glasses combined with teacher incentive). However, in view of lower-than-expected enrollment and our having recently completed a large trial $^{3}$ providing glasses only to similar-aged children, the glasses-only arm was dropped. In October 2013, after the baseline survey and vision screening but prior to refraction, eligible children were randomized by school to receive one of two interventions:

- $\quad$ Free spectacles based on the child's measured refractive power dispensed at school by the study optometrist. A letter informing the parents about the free glasses program and including the child's prescription was sent to parents, and a previously-described ${ }^{3}$ educational intervention directed at teachers and children and promoting spectacle wear was carried out. Additionally, teachers (but not children) in eligible classes were informed that if $>=80 \%$ of children given glasses were wearing them at the time of two un-announced class visits, the teacher would receive a tablet computer (Approximate value USD350; approximate monthly teacher income USD450). This offer was made to Chinese, Mathematics and English teachers (the main academic subjects in Chinese 
primary schools) (Intervention group, 47 schools); or

- A glasses prescription and letter to the parents informing them of the refractive status of their child, with free glasses provided only at the conclusion of the trial, though this was not previously announced. No teacher incentive was offered. (Control group, 47 schools).

Randomization was carried at a central location (Stanford University, Stanford, USA) using R software (R Foundation for Statistical Computing, Vienna, Austria). Participants (students, parents and teachers) and enumerators were not informed of either the overall design of the study or the explicit treatment arm assignment.

\section{Educational Intervention}

This has been described elsewhere in detail. ${ }^{3}$ Children at Intervention group schools watched a video and were given cartoon-based pamphlets and a classroom presentation showing children experiencing the benefits of glasses and teachers explaining that glasses do not harm vision. Teachers viewed a presentation at school on the safety and benefits of glasses, accompanied by a brochure with similar information, and posters with similar content were hung in classrooms.

\section{Outcome Assessment: Glasses wear}

Trained assessment teams consisting of two persons each returned un-announced to each school at 6 weeks and 6 months after distribution of glasses and prescriptions. At these visits, spectacle wear was assessed through unannounced direct examination. The main study outcome was observed wear (that is, glasses actually present on the child's face) at 6 months, and the secondary outcome was self-reported wear at 6 months, assessed on the same occasion. After completing the unannounced direct examination, enumerators also asked sampled children in each school to describe their own spectacle wear (secondary outcome) as "always," "only for studying" or "usually not worn." These study personnel were masked to children's group assignment.

\section{Sample size}

Power calculations were performed using Optimal Design software (http://sitemaker.umich.edu/group-based/optimal_design_software) for clusterrandomization and binary outcome (wear versus non-wear). Based on our earlier trials in similar-aged children, ${ }^{3}$ we assumed an estimated rate of wear of $30 \%$ in the Control and $70 \%$ in the Intervention Group, and a $20 \%$ prevalence of myopia. We determined that 90 schools (45 per group) with one class per school (an average of 50 children, with 10 expected to have myopia) would provide $90 \%$ power to detect the expected difference between groups with an alpha error of 0.05 , intra-class correlation of 0.15 .

\section{Statistical Methods}


We standardized baseline math score to give a mean of 0 and SD of 1. Baseline wear of glasses was defined as being able to produce glasses at school, having being told the day before to bring them, whereas a positive self-report of wear at follow-up was defined as wearing glasses "Always" or "Only for studying." We calculated family wealth by summing the value, as reported in the China Rural Household Survey Yearbook (Department of Rural Surveys, National Bureau of Statistics of China, 2013), of items on the list of 14 owned by the family. Refractive power was defined throughout as the spherical equivalent, spherical power plus half the cylindrical power.

Subsequent to randomization, a number of children either could not undergo refraction due to parental refusal of cycloplegia, or did not meet our refractive and visual criteria to receive glasses (see above). Thus, our analyses were performed in per protocol fashion using the vce (cluster) command in Stata 12.0 (StataCorp, College Station, TX), calculating robust standard errors to adjust for clustering by school. ${ }^{18}$ Our analysis took two forms. In the primary analysis, we used logistic regression to examine the association between baseline variables and observed wear at un-announced visits 6 weeks and 6 months (main outcome) after provision of spectacles and prescriptions. Second, we used multiple logistic regression to determine whether membership in the Intervention Group was associated with observed spectacle wear at 6 weeks and 6 months, adjusting for other baseline factors. These included variables associated with 6 week/6month wear at $\mathrm{p}<=0.20$ (baseline spectacle wear, baseline uncorrected VA, baseline math score, parental education, family migrant status, and parental glasses wear) and those we felt important to adjust for on a theoretical basis (age, sex, rural versus urban residence, status as an only child, belief that wearing glasses harms the vision, family wealth and blackboard use).

\section{Missing Data}

To reduce the inefficiency of estimation due to missing values, we use multiple imputation in Stata to impute data for several data at baseline: rural residence $(n=17)$, beliefs about the potential harm of wearing glasses $(n=4)$, baseline glasses wear $(n=1)$, parental education $(n=10)$, having both parents working in the area $(n=5)$, and family wealth $(n=55)$. We used logistic regression for binary variables and ordered logistic regression for ordinal variable. The independent variables used for imputation included all non-missing variables listed in Table 1 . The multiple imputation approach created 20 copies of the data in which missing values were imputed by chained equations. Final results of multivariate analysis were obtained by averaging these 20 datasets using Rubin's rules, ${ }^{19}$ which ensured that the standard errors for all regression coefficients took into account uncertainty in the imputations and in the estimation. 


\section{Results}

Among 4376 children in selected fifth grade classes in 94 randomly-chosen schools, $3128(71.5 \%)$ were excluded on the basis of having uncorrected visual acuity (VA) $>6 / 12$ in both eyes. At 94 schools, there were 1248 children $(28.5 \%)$ with uncorrected VA $<=6 / 12$ in either eye. A total of 47 schools (639 children, $51.2 \%$ ) were randomized to the Intervention group (free glasses and the teacher incentive), and 47 schools (609 children, $48.8 \%$ ) to the Control group (glasses prescriptions and a note to the parents only). (Figure 1)

A total of 281 children (parents refused refraction 189/639 $=29.6 \%$; VA not correctable to $>=6 / 12$ in both eyes $92 / 639=14.4 \%$ ) were excluded from the Intervention group, and 239 (parents refused refraction $165 / 609=27.1 \%$; VA not correctable to $>=$ $6 / 12$ in both eyes $74 / 609=12.2 \%$ ) from the Controls, leaving 358 children $(49.2 \%)$ at 47 schools allocated to Intervention and 370 children $(50.8 \%)$ at 47 schools allocated to Control. (Figure 1) Children of families refusing refraction were more likely to be boys $(\mathrm{P}=0.003)$ and had better uncorrected VA $(\mathrm{P}=0.003)$ than children whose families accepted, but their age $(p=0.25)$ and rates of spectacle wear $(p=0.71)$ did not differ.

Among the 728 children allocated to the study (mean age [SD] 10.9 [0.9] years, $51.0 \%$ boys), children in the Intervention and Control groups did not differ significantly in any individual-level or cluster-level variables at baseline, including baseline glasses use (17.8\% in the Controls and $17.9 \%$ in the Intervention group, Table 1). Among those allocated in the study, 341 children $(95.3 \%)$ and 352 children $(95.1 \%)$ followed up at 6 months in the Intervention and Control arms respectively, and underwent analysis (Figure 1).

Table 2 shows both directly observed and self-reported glasses use among the treatment groups at the 6 week and 6 month follow-ups, all of which were significantly greater ( $\mathrm{P}<0.001$, two-sample t-test) in the Intervention Group. Observed wear (the primary outcome) was $68.3 \%$ (233/341) and 23.9\% (84/352) among Intervention and Control children respectively at 6 months, while for self-reported wear at 6 months, the figures were $90.6 \%$ (308/340) and 32.1\% (106/330) respectively. A total of 19/47 (40.4\%) Intervention Group schools had spectacle wear rates $>=80 \%$ on both follow-up visits, and teachers at these schools received tablet computers. No Control Group schools achieved this level of wear at either follow-up.

In regression models of factors potentially affecting observed spectacle wear at 6 months, membership in the Intervention group was highly associated with wear $(\mathrm{OR}=$ $11.5,95 \%$ CI 5.91 to $22.5, \mathrm{P}<0.001$ ) (Table 3 ). Other variables significantly associated with observed wear at 6 months in the multivariate model included baseline glasses wear $(\mathrm{OR}=12.2,95 \%$ CI 5.63 to $26.4, \mathrm{P}<0.001)$, uncorrected $\mathrm{VA}<6 / 18$ in both eyes $(\mathrm{OR}=$ $1.70,95 \%$ CI 1.14 to $2.53, \mathrm{P}=0.01)$, parental glasses wear $(\mathrm{OR}=1.90,95 \% \mathrm{CI} 1.14$ to $3.18, \mathrm{P}=0.02)$, and both parents working in the area $(\mathrm{OR}=1.62,95 \% \mathrm{CI} 0.93$ to $2.84, \mathrm{P}$ $=0.09$ ). Membership in the Intervention group was the strongest determinant of selfreported wear in logistic regression models at 6 months $(\mathrm{OR}=43.7,95 \% \mathrm{CI}=21.7-88.5$, $\mathrm{P}<0.001$ ), with other variables generally consistent with the above results (data not shown). 


\section{Discussion}

Whereas previous studies of programs providing free glasses ${ }^{3,6-7}$ and educational interventions to promote spectacle wear ${ }^{3,12}$ have generally shown low uptake, the current report demonstrated that free glasses combined with education on their use and a teacher incentive maintained wear in between two-thirds and $90 \%$ of children needing them over the course of a school year. The impact of the intervention on spectacle wear at 6 months was greater than that of family wealth, parental spectacle wear and children's uncorrected VA. Our main study outcome, observed wear at the time of an un-announced examination, might be expected to under-estimate true daily use of spectacles somewhat. Self-reported wear ("Always" or "For studying") in the Treatment group at 6 months exceeded 90\%, three times that among the Control group.

Previous trials in Africa ${ }^{7}$ and China $^{3}$ have demonstrated a near doubling in rates of spectacle wear among children by providing free glasses rather than requiring that spectacles be purchased. However, the published literature suggests that there are important limits to children's compliance with free spectacles.

Studies on this subject have assessed spectacle use over periods of a month to a year, and relied on a variety of outcomes, including self-reported use, ${ }^{20-2}$ estimates by parents, teachers or health professionals ${ }^{18}$ and directly-observed wear. ${ }^{3,6-7,23-5}$ Observed rates of wear were low, ranging from $13 \%$ to $41 \% .^{3,6-7,21,23-4}$ All of the few studies reporting higher rates $\left(46 \%\right.$ by Keay et al in China, ${ }^{25} 56 \%$ by Vincent et al in Thai refugee camps, ${ }^{22}$ and $58 \%$ by von-Bischhoffshaussen et al in Chile ${ }^{20}$ relied on self-report and/or estimates of teachers or parents, ${ }^{20,22}$ had low $(58-76 \%)$ rates of follow-up ${ }^{20,22}$ or assessment times as short as one month after spectacle distribution. ${ }^{25}$

It would appear that longer-term (over the course of a school year) compliance with free spectacles, as measured by objective indicators such as observed wear at unannounced examinations, is low among children without additional interventions. The highest rate of long-term (6 month) observed compliance identified in our review was $44 \%$ in our own previous trial, ${ }^{3}$ among the sub-group of children receiving free glasses and an educational intervention promoting their wear (wear was $41 \%$ among all children receiving free glasses in the trial). The additional impact of this educational intervention appears to have been modest though, as children not receiving it had only slightly lower observed wear rates of $37 \%$ at 6 months $(\mathrm{P}=0.04)$. An earlier trial of educational interventions promoting spectacle wear in children found no effect. ${ }^{12}$ The current trial is the only one of which we are aware in which a substantial majority of children provided free spectacles were observed to wear them over the course of a school year.

The importance of this study lies in the fact that recent trials have established a significant impact of providing spectacles on children's academic outcomes, even in the face of relatively low compliance with wear. ${ }^{3}$ Given this, successful interventions to motivate regular use of spectacles in the classroom are of particular interest, and it is hoped that additional gains in children's educational outcomes may be realized with improved adherence. Further underscoring the significance of this work are the high reported prevalence of refractive error among Chinese children, ${ }^{26}$ and the very low rates of wear observed among Control children in the current study and in other large surveys among disadvantaged pediatric populations in China. ${ }^{3}$ 
Strengths of the current study include its randomized, controlled design, high (> 95\%) rates of follow-up and randomly-selected cohort from among a social group at risk both for myopia and poor spectacle compliance. These tend to increase confidence in the significance of the results. Limitations must also be acknowledged. Over a quarter of parents (a proportion which did not differ between treatment groups) refused cycloplegic refraction on behalf of their children, a common situation in China when individual parental consent is sought for cycloplegia. Regarding potential impact on the main study outcome, baseline spectacle wear (the most important determinant of wear at 6 months) did not differ between children of families refusing and giving consent, though the former had better uncorrected VA, which was associated with lower rates of wear. Power limitations did not permit us to include a group receiving free spectacles but no teacher incentive, meaning that we could not directly assess the independent impact of the teacher incentive. However, fewer than half of similar-aged children provided free spectacles without teacher incentives were wearing them at 6 months under an identical direct observation protocol in our earlier trial, ${ }^{3}$ conducted in an area with similar low rates of baseline wear.

All participating children attended majority-migrant schools drawn from three nearby eastern Chinese cities, and all of them were at the same grade level in school $\left(5^{\text {th }}\right)$. The particular respect accorded teachers in Confucian cultures suggests that teacher incentives might be particularly well-suited to such societies. For these reasons, application of these results to other settings and age groups must be made with caution. Still, an intervention is of potential value if it can improve spectacle wear in a country where half of the world's children visually disabled by refractive error reside.

For the provision of free glasses and teacher incentives to be a sustainable strategy in China, the government must likely play a substantial role. Our recent trials and the current study provide support for such government action in driving glasses programs, by demonstrating the educational impact ${ }^{3}$ and safety ${ }^{4}$ of glasses wear among children, together with a practical means to achieve high compliance. Pilot programs demonstrating scalable and sustainable school-based models of glasses distribution based on these trials are now under way with collaboration of local governments in Shaanxi, Gansu, Guangdong and Yunnan provinces. In these studies, we are examining incentives based on teachers' evaluations, which can impact salary, as a more sustainable alternative to gifts. It is hoped that wider application of these models can reduce the burden of uncorrected refractive error among children in China's rural areas and large urban migrant populations. 
Acknowledgments

A. Funding/Support: This study was funded by Caterpillar Inc., Essilor-China (Shanghai), Brien Holden Vision Institute, Leibniz Institute of Agricultural Development in Transition Economies (IAMO, Germany), National Natural Science Foundation of China (Grant: 71373255), the Institute of Geographic Sciences and Natural Resources Research, CAS (Grant: 2013RC204, 2012RC102). Prof Congdon is supported by the Chinese government Thousand Man Plan.

B. Financial Disclosures: All authors have completed the ICMJE uniform disclosure form at www.icmje.org/coi_disclosure.pdf and declare: The free spectacles used in this study were supplied by Essilor-China, producers of frames and lenses in China who also provided financial support for the study; the authors have no other financial relationships to disclose.

C. Other Acknowledgments: None. 
1. Resnikoff S, Pascolini D, Mariotti SP, Pokharel GP. Global magnitude of visual impairment caused by uncorrected refractive errors in 2004. Bull World Health Organ. 2008;86(1):63-70.

2. Congdon NG, Wang Y, Song Y et al.. Visual disability, visual function and myopia among rural Chinese secondary school children: the Xichang Pediatric Refractive Error Study (X-PRES) Report \#1. Invest Ophthalmol Vis Sci. 2008;49(7):2888-94.

3. Ma X, Zhou Z, Yi H, et al. Effect of providing free glasses on children's educational outcomes in China. Cluster-randomized controlled trial. BMJ. 2014;349:g5740.

4. Congdon N, Ma X, Yi H et al. Safety of Spectacles for Children's Vision: A ClusterRandomized Controlled Trial. (Under review).

5. Esteso P, Castanon A, Toledo S et al. Correction of Moderate Myopia Is Associated with Improvement in Self-Reported Visual Functioning among Mexican School-Aged Children. Invest Ophthalmol Vis Sci. 2007;48(11):4949-4954.

6. Castanon Holguin AM, Congdon $\mathrm{N}$ et al. Factors associated with spectacle-wear compliance in school-aged Mexican children. Invest Ophthalmol Vis Sci. 2006;47(3):925-8.

7. Wedner S, Masanja H, Bowman R, Todd J, Gilbert C. Two strategies for correcting refractive errors in school students in Tanzania: randomised comparison, with implications for screening programmes. Br J Ophthalmol. 2008;92(1):19-24.

8. Li L, Lam J, Lu Y, et al. Attitudes of students, parents, and teachers towards glasses use in rural China. Arch Ophthalmol. 2010;128(6):759-65.

9. Odedra N, Wedner SH, Shigongo ZS, Nyalali K, Gilbert C. Barriers to spectacle use in Tanzanian secondary school students. Ophthalmic Epidemiol. 2008;15(6):410-7

10. Congdon N, Zheng MW, Sharma A et al. Prevalence and determinants of spectacle nonwear among rural Chinese secondary schoolchildren: The Xichang Pediatric Refractive Error Study Report 3. Arch Ophthalmol. 2008;126(12):1717-1723.

11. Li LP, Song Y, Liu XJ et al.. Spectacle uptake among secondary school students with visually-significant refractive error in rural China: The Xichang Pediatric Refractive Error Study (X-PRES) Report \#5. Invest Ophthalmol Vis Sci. 2008;49(7):2895-902.

12. Congdon N, Li L, Zhang M et al. Randomized, controlled trial of an educational intervention to promote spectacle use in rural China: The See Well to Learn Well Study. Ophthalmology 2011;118(12):2343-50. 
13. Shanghai issues report on migrant population. http://www.chinadaily.com.cn/china/2013-07/02/content_16710313.htm. Accessed 21 January 2015.

14. Suzhou population tops 13 million, half being migrants. http://livingsu.com/news_detail.asp?id=1527\#.VL8bpvmSx8E. Accessed 21 January 2015.

15. Lai F, Liu C, Luo R et al. The Education of China's Migrant Children: The Missing Link in China's Education System. International Journal of Education Development. 2014;37:68-77.

16. Congdon N, Patel N, Esteso P et al. The association between refractive cutoffs for spectacle provision and visual improvement among school-aged children in South Africa. Br J Ophthalmol. 2008;92(1):13-8.

17. Ferris FL 3rd, Kassoff A, Bresnick GH, Bailey I. New visual acuity charts for clinical research. Am J Ophthalmol. 1982;94(1):91-6.

18. Hosmer DW, Lemeshow S. Applied logistic regression. John Wiley \& Sons, 2004, New York.

19. Rubin DB. Multiple Imputation for Nonresponse in Surveys. J. Wiley \& Sons, 1987, New York.

20. von-Bischhoffshausen FB, Muñoz B, Riquelme A, Ormeño MJ, Silva JC. Spectaclewear compliance in school children in Concepción Chile. Ophthalmic

Epidemiol. 2014;21(6):362-9.

21. Aldebasi YH. A descriptive study on compliance of spectacle-wear in children of primary schools at Qassim Province, Saudi Arabia. Int J Health Sci (Qassim). 2013;7(3):291-9.

22. Vincent JE, Netek S, Parry A, Mladenovich D, Thein NN, Amendola PR. Reported wearing compliance of ready-made spectacles at 6 and 12 months. Optom Vis Sci. 2010;87(12):958-65.

23. Messer DH, Mitchell GL, Twelker JD, Crescioni M; CLEERE Study Group. Spectacle wear in children given spectacles through a school-based program. Optom Vis Sci. 2012;89(1):19-26. 
24. Gogate P, Mukhopadhyaya D, Mahadik A et al. Spectacle compliance amongst rural secondary school children in Pune district, India. Indian J Ophthalmol. 2013;61(1):8-12.

25. Keay L, Zeng Y, Munoz B, He M, Friedman DS. Predictors of early acceptance of free spectacles provided to junior high school students in China. Arch Ophthalmol. 2010;128(10):1328-34

26. Morgan IG, Ohno-Matsui K, Saw SM. Myopia. Lancet. 2012;379(9827):1739-48. 
Figure Legend

Figure 1: Flowchart for enrollment and allocation of children with refractive error in a randomized trial of free glasses and teacher incentives to promote spectacle wear 
Table 1| Baseline Characteristics of 728 Children with Correctable Refractive Error by Group Assignment. Values are Mean (SD) unless Stated otherwise

\begin{tabular}{|c|c|c|c|c|}
\hline Variable & $\begin{array}{c}\text { Control } \\
\text { group } \\
(\mathrm{n}=370 \text { at } 47 \\
\text { schools })\end{array}$ & $\begin{array}{c}\text { Intervention } \\
\text { group } \\
(\mathrm{n}=358 \text { at } \\
47 \text { schools })\end{array}$ & $\begin{array}{c}\text { P-value } \\
\text { Control vs } \\
\text { Intervention }\end{array}$ & $\begin{array}{l}\text { Missing } \\
\text { data } \\
\text { Number } \\
(\%)\end{array}$ \\
\hline Age, years & $\begin{array}{l}11.0 \\
(1.0)\end{array}$ & $\begin{array}{l}10.9 \\
(0.9) \\
\end{array}$ & 0.80 & $0(0.0)$ \\
\hline Male sex $(\mathrm{N}, \%)$ & $\begin{array}{c}191 \\
(51.6)\end{array}$ & $\begin{array}{c}180 \\
(50.3)\end{array}$ & 0.71 & $0(0.0)$ \\
\hline Rural residence $(\mathrm{N}, \%)$ & $\begin{array}{c}320 \\
(88.2)\end{array}$ & $\begin{array}{c}295 \\
(84.8) \\
\end{array}$ & 0.26 & $17(2.3)$ \\
\hline Only child in family $(\mathrm{N}, \%)$ & $\begin{array}{c}74 \\
(20.0) \\
\end{array}$ & $\begin{array}{c}70 \\
(19.6)\end{array}$ & 0.91 & $0(0.0)$ \\
\hline $\begin{array}{l}\text { Believes wearing glasses } \\
\text { harms vision }(\mathrm{N}, \%)\end{array}$ & $\begin{array}{c}127 \\
(34.5)\end{array}$ & $\begin{array}{c}118 \\
(33.1)\end{array}$ & 0.72 & $4(0.5)$ \\
\hline $\begin{array}{l}\text { Wearing glasses at baseline } \\
(\mathrm{N}, \%)^{*}\end{array}$ & $\begin{array}{c}66 \\
(17.8) \\
\end{array}$ & $\begin{array}{c}64 \\
(17.9) \\
\end{array}$ & 0.98 & $1(0.1)$ \\
\hline VA $<6 / 18$ both eyes & $\begin{array}{c}164 \\
(44.3) \\
\end{array}$ & $\begin{array}{c}142 \\
(39.7) \\
\end{array}$ & 0.24 & $0(0.0)$ \\
\hline Math score, SD & $0.1(1.0)$ & $0.2(1.0)$ & 0.83 & $0(0.0)$ \\
\hline $\begin{array}{l}\text { At least one parent with > } \\
12 \text { years education } N(\%)\end{array}$ & $\begin{array}{c}112 \\
(30.7) \\
\end{array}$ & $\begin{array}{c}108 \\
(30.6) \\
\end{array}$ & 0.98 & $10(1.4)$ \\
\hline $\begin{array}{l}\text { Both parents working in the } \\
\text { area } \mathrm{N}(\%)\end{array}$ & $\begin{array}{c}323 \\
(87.8) \\
\end{array}$ & $\begin{array}{c}299 \\
(84.2) \\
\end{array}$ & 0.18 & $5(0.8)$ \\
\hline $\begin{array}{l}\text { At least one parent wears } \\
\text { glasses }\end{array}$ & $\begin{array}{c}65 \\
(17.6) \\
\end{array}$ & $\begin{array}{c}70 \\
(19.6)\end{array}$ & 0.56 & $1(0.1)$ \\
\hline Family wealth N (\%) & & & 0.14 & $55(8.0)$ \\
\hline Top tercile & $\begin{array}{c}101 \\
(29.4)\end{array}$ & $\begin{array}{c}114 \\
(35.1) \\
\end{array}$ & & \\
\hline Middle tercile & $\begin{array}{c}120 \\
(35.0)\end{array}$ & $\begin{array}{c}110 \\
(33.8)\end{array}$ & & \\
\hline Bottom tercile & $\begin{array}{c}122 \\
(35.6)\end{array}$ & $\begin{array}{c}101 \\
(31.1)\end{array}$ & & \\
\hline Blackboard use $\mathrm{N}(\%)$ & & & 0.52 & $0(0.0)$ \\
\hline$<$ Half of teaching & $\begin{array}{c}12 \\
(25.5) \\
\end{array}$ & $\begin{array}{c}16 \\
(34.0) \\
\end{array}$ & & \\
\hline Half of teaching & $\begin{array}{c}19 \\
(40.4)\end{array}$ & $\begin{array}{c}16 \\
(34.0)\end{array}$ & & \\
\hline$>$ Half of teaching & $\begin{array}{c}16 \\
(34.0) \\
\end{array}$ & $\begin{array}{c}15 \\
(31.9) \\
\end{array}$ & & \\
\hline $\begin{array}{l}\text { *Defined as being able } \\
\text { to produce glasses at } \\
\text { school, having been told the } \\
\text { day before to bring them. }\end{array}$ & & & & \\
\hline
\end{tabular}


Table 2 Glasses Use at Six Week and Six Month Follow-up in Each Group of Children with Refractive Error

Six week follow-up Six month follow-up

$$
(\mathrm{N}=715) \quad(\mathrm{N}=693)
$$

Directly observed glasses use (Primary outcome)

\begin{tabular}{lcc}
\hline Control & $60 / 363$ & $84 / 352$ \\
$\mathrm{~N}(\%)$ & $(16.5)$ & $(23.9)$ \\
\hline Intervention & $287 / 352$ & $233 / 341$ \\
$\mathrm{~N}(\%)$ & $(81.5)$ & $(68.3)$ \\
\hline P-value comparing Control & $<0.001$ & $<0.001$ \\
And Intervention Groups* & & \\
\hline Self reported glasses use & & \\
\hline Control & & $106 / 330$ \\
$\mathrm{~N}(\%)$ & $97 / 361$ & $(32.1)$ \\
\hline Intervention & $(26.9)$ & $308 / 340$ \\
$\mathrm{~N}(\%)$ & $321 / 350$ & $(90.6)$ \\
\hline P-value comparing Control & $(91.7)$ & $<0.001$ \\
And Intervention Groups* & $<0.001$ & \\
\hline
\end{tabular}

*Two-sample t-test 
Table 3| Logistic Regression Analysis of Factors Potentially Affecting Observed Wear of Spectacles at 6 Months (Main Study Outcome) Among Children with Refractive Error.

Variables with a Statistically Significant Association with Observed Wear at Six Months are Highlighted in Bold.

\begin{tabular}{|c|c|c|c|c|c|c|}
\hline \multirow[b]{2}{*}{ Variable } & \multicolumn{3}{|c|}{ Univariate analysis $(\mathrm{N}=693)$} & \multicolumn{3}{|c|}{ Multivariate analysis $(\mathrm{N}=693)$} \\
\hline & OR & $\begin{array}{c}95 \% \\
\text { confidence } \\
\text { interval }\end{array}$ & P-value & OR & $\begin{array}{c}95 \% \\
\text { confidence } \\
\text { interval }\end{array}$ & P-value \\
\hline Intervention group & 6.88 & $4.09-11.6$ & $<0.001$ & 11.5 & $5.91-22.5$ & $<0.001$ \\
\hline Age (Years) & 0.87 & $0.72-1.05$ & 0.16 & 0.95 & $0.77-1.18$ & 0.64 \\
\hline Male sex & 1.04 & $0.75-1.43$ & 0.82 & 0.92 & $0.64-1.33$ & 0.67 \\
\hline Rural residence & 0.67 & $0.42-1.07$ & 0.10 & 0.88 & $0.50-1.53$ & 0.65 \\
\hline Only child in family & 1.36 & $0.92-2.00$ & 0.12 & 1.02 & $0.65-1.60$ & 0.92 \\
\hline $\begin{array}{l}\text { Believes wearing } \\
\text { glasses harms vision } \\
(\mathrm{N}, \%)\end{array}$ & 1.23 & $0.89-1.69$ & 0.21 & 1.17 & $0.79-1.73$ & 0.44 \\
\hline $\begin{array}{l}\text { Wearing glasses at } \\
\text { baseline }\end{array}$ & 8.17 & $4.50-14.9$ & $<0.001$ & 12.2 & $5.63-26.4$ & $<0.001$ \\
\hline $\mathrm{VA}<6 / 18$ both eyes & 2.08 & 1.49 - 2.89 & $<0.001$ & $\mathbf{1 . 7 0}$ & $1.14-2.53$ & 0.01 \\
\hline Math score & 1.13 & $0.92-1.40$ & 0.25 & 1.19 & $0.95-1.49$ & 0.12 \\
\hline $\begin{array}{l}\text { At least one parent } \\
\text { with }>12 \text { years } \\
\text { education }\end{array}$ & 1.44 & $1.01-2.04$ & 0.04 & 1.31 & $0.85-2.00$ & 0.22 \\
\hline $\begin{array}{l}\text { At least one parent } \\
\text { wears glasses }\end{array}$ & 1.78 & $1.15-2.74$ & $<0.001$ & 1.90 & $1.14-3.18$ & 0.02 \\
\hline $\begin{array}{l}\text { Both parents working } \\
\text { in the area }\end{array}$ & 1.16 & $0.77-1.75$ & 0.47 & 1.62 & $0.93-2.84$ & 0.09 \\
\hline
\end{tabular}

Family Wealth (Bottom tercile as reference)

\begin{tabular}{l|c|c|c|c|c|c}
\hline Top tercile & 1.15 & $0.81-1.63$ & 0.42 & 1.08 & $0.68-1.71$ & 0.76 \\
\hline Middle tercile & 1.11 & $0.81-1.52$ & 0.53 & 1.15 & $0.75-1.77$ & 0.53 \\
\hline
\end{tabular}

Blackboard use (Less than half of teaching as reference)

\begin{tabular}{c|c|c|c|c|c|c}
\hline Half of teaching & 0.89 & $0.49-1.62$ & 0.71 & 1.08 & $0.50-2.32$ & 0.85 \\
\hline$>$ Half of teaching & 0.95 & $0.48-1.91$ & 0.89 & 1.02 & $0.46-2.27$ & 0.96
\end{tabular}




\section{Click here to download high resolution image}

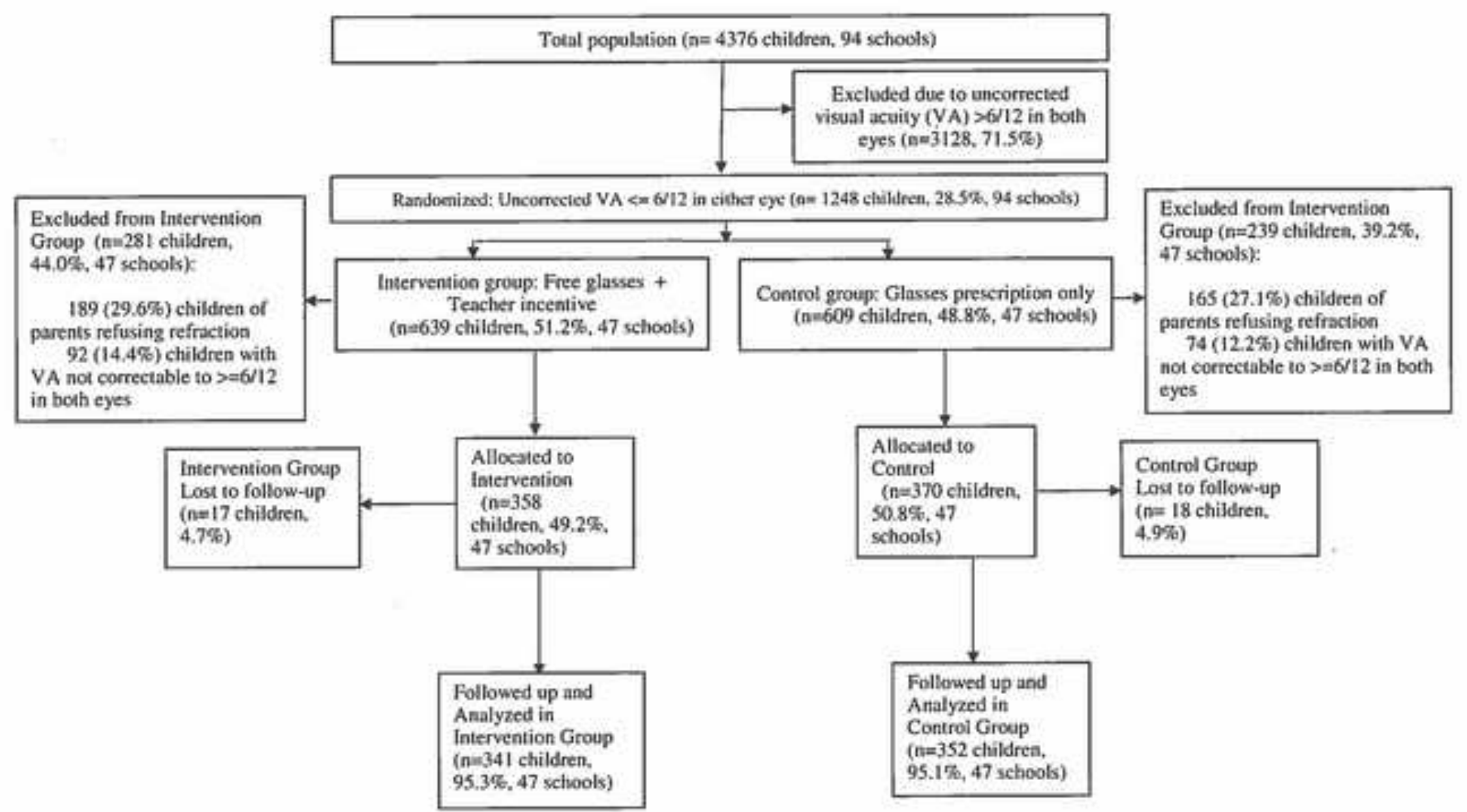


Impact of Free Glasses and a Teacher Incentive on Children's Use of Eyeglasses: A Cluster-Randomized Controlled Trial

MS \#: AJO-15-534

Free spectacle distribution and teacher incentives maintained classroom wear in 68-90\% of children needing glasses over a school year in this cluster-randomized trial. Very low rates of wear (24-32\%) among Control children demonstrated the need for these interventions. 


\section{Please wait...}

If this message is not eventually replaced by the proper contents of the document, your PDF viewer may not be able to display this type of document.

You can upgrade to the latest version of Adobe Reader for Windows®, Mac, or Linux ${ }^{\circledR}$ by visiting http://www.adobe.com/go/reader_download.

For more assistance with Adobe Reader visit http://www.adobe.com/go/acrreader.

Windows is either a registered trademark or a trademark of Microsoft Corporation in the United States and/or other countries. Mac is a trademark of Apple Inc., registered in the United States and other countries. Linux is the registered trademark of Linus Torvalds in the U.S. and other countries. 


\section{Please wait...}

If this message is not eventually replaced by the proper contents of the document, your PDF viewer may not be able to display this type of document.

You can upgrade to the latest version of Adobe Reader for Windows®, Mac, or Linux ${ }^{\circledR}$ by visiting http://www.adobe.com/go/reader_download.

For more assistance with Adobe Reader visit http://www.adobe.com/go/acrreader.

Windows is either a registered trademark or a trademark of Microsoft Corporation in the United States and/or other countries. Mac is a trademark of Apple Inc., registered in the United States and other countries. Linux is the registered trademark of Linus Torvalds in the U.S. and other countries. 


\section{Please wait...}

If this message is not eventually replaced by the proper contents of the document, your PDF viewer may not be able to display this type of document.

You can upgrade to the latest version of Adobe Reader for Windows ${ }$, Mac, or Linux ${ }^{\circledR}$ by visiting http://www.adobe.com/go/reader_download.

For more assistance with Adobe Reader visit http://www.adobe.com/go/acrreader.

Windows is either a registered trademark or a trademark of Microsoft Corporation in the United States and/or other countries. Mac is a trademark of Apple Inc., registered in the United States and other countries. Linux is the registered trademark of Linus Torvalds in the U.S. and other countries. 


\section{Please wait...}

If this message is not eventually replaced by the proper contents of the document, your PDF viewer may not be able to display this type of document.

You can upgrade to the latest version of Adobe Reader for Windows ${ }$, Mac, or Linux ${ }^{\circledR}$ by visiting http://www.adobe.com/go/reader_download.

For more assistance with Adobe Reader visit http://www.adobe.com/go/acrreader.

Windows is either a registered trademark or a trademark of Microsoft Corporation in the United States and/or other countries. Mac is a trademark of Apple Inc., registered in the United States and other countries. Linux is the registered trademark of Linus Torvalds in the U.S. and other countries. 


\section{Please wait...}

If this message is not eventually replaced by the proper contents of the document, your PDF viewer may not be able to display this type of document.

You can upgrade to the latest version of Adobe Reader for Windows ${ }$, Mac, or Linux ${ }^{\circledR}$ by visiting http://www.adobe.com/go/reader_download.

For more assistance with Adobe Reader visit http://www.adobe.com/go/acrreader.

Windows is either a registered trademark or a trademark of Microsoft Corporation in the United States and/or other countries. Mac is a trademark of Apple Inc., registered in the United States and other countries. Linux is the registered trademark of Linus Torvalds in the U.S. and other countries. 


\section{Please wait...}

If this message is not eventually replaced by the proper contents of the document, your PDF viewer may not be able to display this type of document.

You can upgrade to the latest version of Adobe Reader for Windows ${ }$, Mac, or Linux ${ }^{\circledR}$ by visiting http://www.adobe.com/go/reader_download.

For more assistance with Adobe Reader visit http://www.adobe.com/go/acrreader.

Windows is either a registered trademark or a trademark of Microsoft Corporation in the United States and/or other countries. Mac is a trademark of Apple Inc., registered in the United States and other countries. Linux is the registered trademark of Linus Torvalds in the U.S. and other countries. 


\section{Please wait...}

If this message is not eventually replaced by the proper contents of the document, your PDF viewer may not be able to display this type of document.

You can upgrade to the latest version of Adobe Reader for Windows ${ }$, Mac, or Linux ${ }^{\circledR}$ by visiting http://www.adobe.com/go/reader_download.

For more assistance with Adobe Reader visit http://www.adobe.com/go/acrreader.

Windows is either a registered trademark or a trademark of Microsoft Corporation in the United States and/or other countries. Mac is a trademark of Apple Inc., registered in the United States and other countries. Linux is the registered trademark of Linus Torvalds in the U.S. and other countries. 


\section{Please wait...}

If this message is not eventually replaced by the proper contents of the document, your PDF viewer may not be able to display this type of document.

You can upgrade to the latest version of Adobe Reader for Windows ${ }$, Mac, or Linux ${ }^{\circledR}$ by visiting http://www.adobe.com/go/reader_download.

For more assistance with Adobe Reader visit http://www.adobe.com/go/acrreader.

Windows is either a registered trademark or a trademark of Microsoft Corporation in the United States and/or other countries. Mac is a trademark of Apple Inc., registered in the United States and other countries. Linux is the registered trademark of Linus Torvalds in the U.S. and other countries. 


\section{Please wait...}

If this message is not eventually replaced by the proper contents of the document, your PDF viewer may not be able to display this type of document.

You can upgrade to the latest version of Adobe Reader for Windows ${ }$, Mac, or Linux ${ }^{\circledR}$ by visiting http://www.adobe.com/go/reader_download.

For more assistance with Adobe Reader visit http://www.adobe.com/go/acrreader.

Windows is either a registered trademark or a trademark of Microsoft Corporation in the United States and/or other countries. Mac is a trademark of Apple Inc., registered in the United States and other countries. Linux is the registered trademark of Linus Torvalds in the U.S. and other countries. 


\section{Please wait...}

If this message is not eventually replaced by the proper contents of the document, your PDF viewer may not be able to display this type of document.

You can upgrade to the latest version of Adobe Reader for Windows®, Mac, or Linux ${ }^{\circledR}$ by visiting http://www.adobe.com/go/reader_download.

For more assistance with Adobe Reader visit http://www.adobe.com/go/acrreader.

Windows is either a registered trademark or a trademark of Microsoft Corporation in the United States and/or other countries. Mac is a trademark of Apple Inc., registered in the United States and other countries. Linux is the registered trademark of Linus Torvalds in the U.S. and other countries. 


\section{Please wait...}

If this message is not eventually replaced by the proper contents of the document, your PDF viewer may not be able to display this type of document.

You can upgrade to the latest version of Adobe Reader for Windows ${ }$, Mac, or Linux ${ }^{\circledR}$ by visiting http://www.adobe.com/go/reader_download.

For more assistance with Adobe Reader visit http://www.adobe.com/go/acrreader.

Windows is either a registered trademark or a trademark of Microsoft Corporation in the United States and/or other countries. Mac is a trademark of Apple Inc., registered in the United States and other countries. Linux is the registered trademark of Linus Torvalds in the U.S. and other countries. 


\section{Please wait...}

If this message is not eventually replaced by the proper contents of the document, your PDF viewer may not be able to display this type of document.

You can upgrade to the latest version of Adobe Reader for Windows ${ }$, Mac, or Linux ${ }^{\circledR}$ by visiting http://www.adobe.com/go/reader_download.

For more assistance with Adobe Reader visit http://www.adobe.com/go/acrreader.

Windows is either a registered trademark or a trademark of Microsoft Corporation in the United States and/or other countries. Mac is a trademark of Apple Inc., registered in the United States and other countries. Linux is the registered trademark of Linus Torvalds in the U.S. and other countries. 


\section{CONSORT 2010 checklist of information to include when reporting a randomised trial*}

\begin{tabular}{|c|c|c|c|}
\hline Section/Topic & $\begin{array}{l}\text { Item } \\
\text { No }\end{array}$ & Checklist item & $\begin{array}{l}\text { Reported } \\
\text { on page No }\end{array}$ \\
\hline \multicolumn{4}{|l|}{ Title and abstract } \\
\hline & $1 \mathrm{a}$ & Identification as a randomised trial in the title & 1 \\
\hline & $1 b$ & Structured summary of trial design, methods, results, and conclusions (for specific guidance see CONSORT for abstracts) & $2-3$ \\
\hline \multicolumn{4}{|l|}{ Introduction } \\
\hline \multirow{2}{*}{$\begin{array}{l}\text { Background and } \\
\text { objectives }\end{array}$} & $2 a$ & Scientific background and explanation of rationale & $4-5$ \\
\hline & $2 b$ & Specific objectives or hypotheses & 5 \\
\hline \multicolumn{4}{|l|}{ Methods } \\
\hline \multirow[t]{2}{*}{ Trial design } & $3 a$ & Description of trial design (such as parallel, factorial) including allocation ratio & $8-9$ \\
\hline & $3 b$ & Important changes to methods after trial commencement (such as eligibility criteria), with reasons & $\mathrm{N} / \mathrm{A}$ \\
\hline \multirow[t]{2}{*}{ Participants } & $4 a$ & Eligibility criteria for participants & 7 \\
\hline & $4 b$ & Settings and locations where the data were collected & 6-7 \\
\hline Interventions & 5 & $\begin{array}{l}\text { The interventions for each group with sufficient details to allow replication, including how and when they were } \\
\text { actually administered }\end{array}$ & $8-9$ \\
\hline \multirow[t]{2}{*}{ Outcomes } & $6 a$ & $\begin{array}{l}\text { Completely defined pre-specified primary and secondary outcome measures, including how and when they } \\
\text { were assessed }\end{array}$ & 10 \\
\hline & $6 b$ & Any changes to trial outcomes after the trial commenced, with reasons & $\mathrm{N} / \mathrm{A}$ \\
\hline \multirow[t]{2}{*}{ Sample size } & $7 a$ & How sample size was determined & 10 \\
\hline & $7 b$ & When applicable, explanation of any interim analyses and stopping guidelines & $\mathrm{N} / \mathrm{A}$ \\
\hline \multicolumn{4}{|l|}{ Randomisation: } \\
\hline \multirow{2}{*}{$\begin{array}{l}\text { Sequence } \\
\text { generation }\end{array}$} & $8 a$ & Method used to generate the random allocation sequence & 9 \\
\hline & $8 b$ & Type of randomisation; details of any restriction (such as blocking and block size) & 9 \\
\hline $\begin{array}{l}\text { Allocation } \\
\text { concealment } \\
\text { mechanism }\end{array}$ & 9 & $\begin{array}{l}\text { Mechanism used to implement the random allocation sequence (such as sequentially numbered containers), } \\
\text { describing any steps taken to conceal the sequence until interventions were assigned }\end{array}$ & 9 \\
\hline Implementation & 10 & $\begin{array}{l}\text { Who generated the random allocation sequence, who enrolled participants, and who assigned participants to } \\
\text { interventions }\end{array}$ & 9 \\
\hline Blinding & $11 \mathrm{a}$ & If done, who was blinded after assignment to interventions (for example, participants, care providers, those & 9 \\
\hline
\end{tabular}


assessing outcomes) and how

$11 \mathrm{~b}$ If relevant, description of the similarity of interventions

Statistical methods

$12 \mathrm{a}$

$12 \mathrm{~b}$

Statistical methods used to compare groups for primary and secondary outcomes

Methods for additional analyses, such as subgroup analyses and adjusted analyses

13a For each group, the numbers of participants who were randomly assigned, received intended treatment, and were analysed for the primary outcome

13b For each group, losses and exclusions after randomisation, together with reasons

14a Dates defining the periods of recruitment and follow-up

14b Why the trial ended or was stopped

15 A table showing baseline demographic and clinical characteristics for each group

Baseline data

Numbers analysed

16

For each group, number of participants (denominator) included in each analysis and whether the analysis was by original assigned groups

Outcomes and

estimation

17a For each primary and secondary outcome, results for each group, and the estimated effect size and its precision (such as 95\% confidence interval)

17b For binary outcomes, presentation of both absolute and relative effect sizes is recommended

Ancillary analyses

18

Results of any other analyses performed, including subgroup analyses and adjusted analyses, distinguishing pre-specified from exploratory

Harms

All important harms or unintended effects in each group (for specific guidance see CONSORT for harms)

\section{Discussion}

Limitations

Generalisability

Interpretation

\section{Other information}

Registration

Protocol

Funding
20 Trial limitations, addressing sources of potential bias, imprecision, and, if relevant, multiplicity of analyses

21 Generalisability (external validity, applicability) of the trial findings

22 Interpretation consistent with results, balancing benefits and harms, and considering other relevant evidence

23 Registration number and name of trial registry

24 Where the full trial protocol can be accessed, if available

25 Sources of funding and other support (such as supply of drugs), role of funders
Fig 1, p. 12

\begin{tabular}{c}
\hline Fig $1, \mathrm{p} 12$ \\
\hline $8,9,10$ \\
\hline 10 \\
\hline Table 1 \\
\hline Table 3, p. 13 \\
\hline
\end{tabular}

Table 3, P. 13

Table 3, P. 13

Table 3, p. 13

\begin{tabular}{c}
\hline $\mathrm{N} / \mathrm{A}$ \\
\hline $17-18$ \\
\hline $17-18$ \\
\hline $17-18$ \\
\hline
\end{tabular}

$\begin{array}{r}1 \\ \hline 1 \\ \hline 1\end{array}$

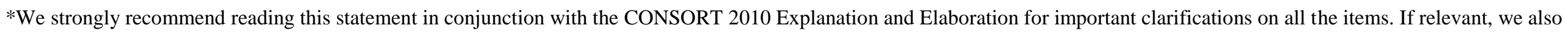

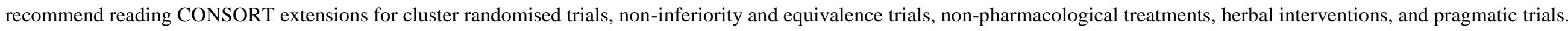
Additional extensions are forthcoming: for those and for up to date references relevant to this checklist, see $\underline{\text { www.consort-statement.org. }}$ 
Biosketch

Hongmei Yi is an associate professor at the Center for Chinese Agricultural Policy of the Chinese Academy of Sciences, Beijing, China. She received her Ph.D. in agricultural economics from the Chinese Academy of Sciences in 2009. Her primary research interests are evaluation of the impact of health programs in rural China and improving the design of the policy for better quality of healthcare delivery. She has published more than 30 peer reviewed articles. 
Biosketch Photo: File name must be authors $n$
Click here to download high resolution image

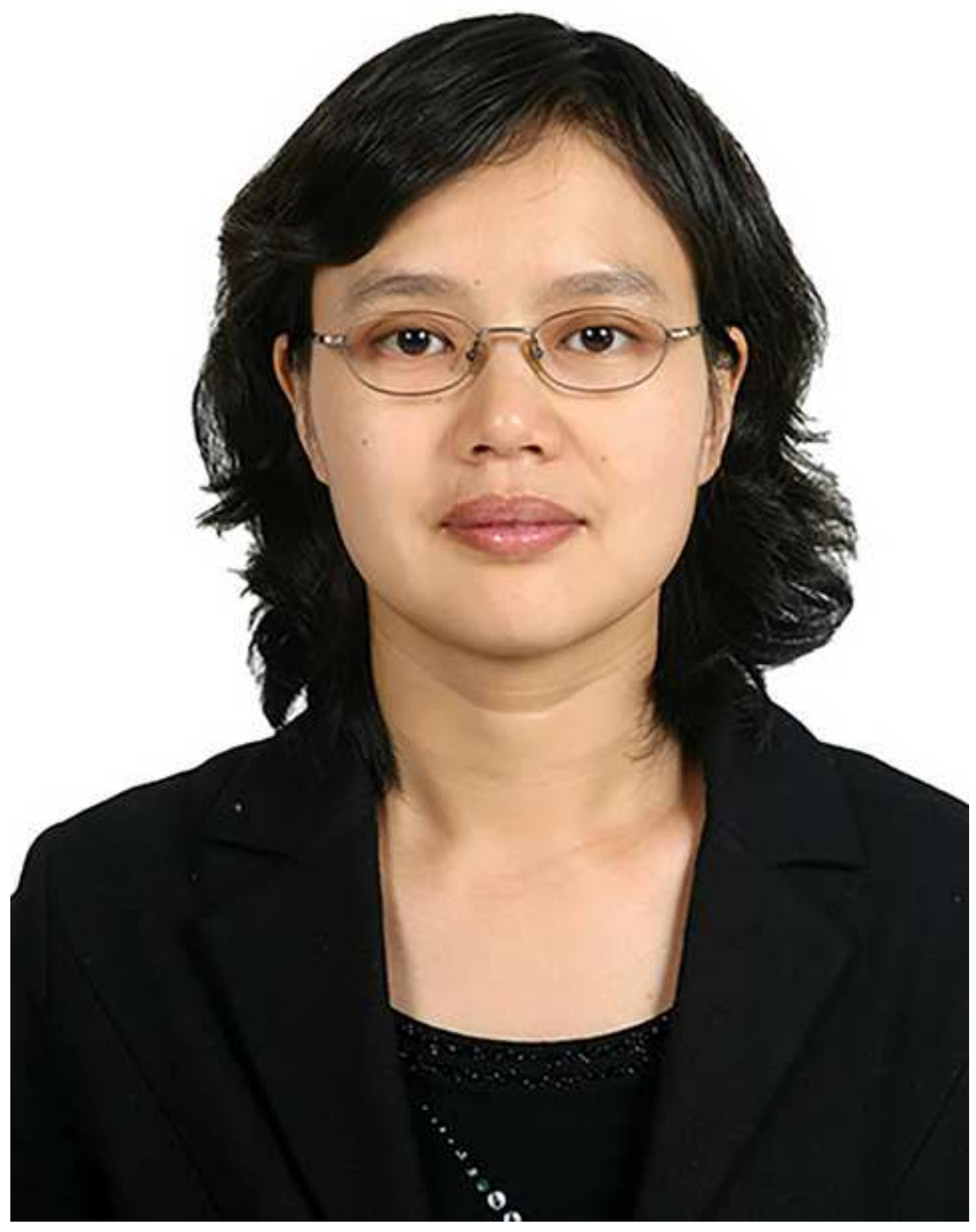

